\title{
Job Order Contracting Performance and Industry Analysis
}

\author{
Jake Gunnoe (M.S.) ${ }^{1}$ and Dean T. Kashiwagi (Ph.D., P.E.) ${ }^{2}$ \\ Jacob Kashiwagi, (Ph.D., P.E. $)^{3}$, BOLD ${ }^{4}$ \\ ${ }^{1,2,3,4}$ School of Sustainable Engineering and the Built Environment, Arizona State University at Tempe, $660 \mathrm{~S}$ \\ College Ave., Tempe, AZ 85281, United States
}

\begin{abstract}
The construction industry has had difficulty in delivering projects efficiently, in a timely manner and within budget. Approximately 2.5\% of all global projects are delivered on time and on budget. Over the past 24 years, research has been conducted at Arizona State University to identify the source of project inefficiencies. As a result of 1800+ tests, researchers have concluded that a primary cause in low project performance (time, cost and customer satisfaction) is the traditional owner-vendor relationship in which the owner uses a design, bid and build $(D B B)$ approach. The industry has come up with other approaches such as design-build $(D B)$ and construction management @ risk (CMAR) in hopes of decreasing the delivery time and lowering the project cost. However, in the latest industry study done comparing the different approaches, there are still no significant conclusions about which process is the most efficient. Deductive logic identifies that the contractor typically has more expertise than the owner does. Research shows that "low bid" and MDC could increase project costs and time up to 30\%. Job Order Contracting (JOC) is a delivery system focused on minimizing the owner's repeated design and procurements and $M D C$ on projects, by enabling a greater utilization of vendor expertise. This report examines the perspective of 47 owners and 13 contractors who have collectively delivered over $\$ 5$ billion of construction services in JOC projects. The results of this survey effort suggest that JOC users are highly satisfied with its overall performance and are seeing better project outcomes and cost savings compared to more traditional methodologies.
\end{abstract}

Keywords: Job Order Contracting, construction industry, delivery methods, design-build, CMAR

\section{Introduction}

Over the past three decades, the construction industry has had issues delivering high performing services (on time, on budget, high quality). Research has shown that the industry as a whole is under-performing (Adrian, 2001; CFMA, 2006; Chikuni and Hendrik, 2012; Kashiwagi, and Parmar, 2004; Leicht, et. al., 2015; Lepartner, 2007; Ohrn, 2009; UK Construction Industry, 2011). The Construction Industry Institute (CII) identified that only approximately $2.5 \%$ of all global projects are delivered on time and on budget (PwC, 2009). Project inefficiencies are estimated to cost between $\$ 15.6$ and $\$ 36$ billion per year (Lepatner, 2007). Multiple delivery methods and solutions have been proposed to solve the non-performance issues of the traditional design-bid-build (DBB) process. They are as follows (AGCA, 2004; Gransberg, et. al. 2006; Kashiwagi, D. 2015b; Konchar, and Sanvido, 1998; Ohrn, 2009):

- Design-Build (DB)

- Design-Bid-Build (DBB)

- Construction Management at Risk (CM@Risk)

- Indefinite Delivery/Indefinite Quantity (IDIQ)

- Job Order Contracting (JOC)

- $\quad$ Time and materials $(\mathrm{T} \& \mathrm{M})$

- Integrated Project Delivery (IPD)

- Public Private Partnerships (PPP)

\section{Design-Bid-Build:}

The traditional process was the design-bid-build (DBB) process. Due to its problems of contractors blaming faulty design and designers blaming faulty construction, the industry came up with the design-build process. The design build process identified one design build team that worked together. This eliminates the blaming between contractors and designers. However, it required the owner to identify what they wanted to build, select a contractor based on a proposal, which identified the end-product and the lump sum price, then sign one contract with the general contractor [who had the designer on their staff]. With this system, the contractor and the designer could not 
blame each other. However, a contention arose because the owner wanted to change the scope of the deliverable after selection of a vendor who had a fixed price and deliverable. The owner felt that the designer, who now worked for the contractor, was not acting in their best interest. Therefore, the industry came up with the construction manager at risk (CM@Risk) approach. In this approach, the owner hired both the contractor and the designer, writing two different contracts. This brought the control of the scope back to the owner. At the same time the general contractor (GC) [who is the construction manager] works with the designer from the very beginning to ensure constructability, that the cost stayed within the budget, and that the final design would be delivered for a guaranteed maximum price [GMP] which the contractor would sign a construction contract. However, the general contractor (GC) cannot be held responsible for design errors. Even if the GC had reviewed the drawings they cannot be penalized for design errors, [only designers have errors and omissions insurance]. Therefore, a guaranteed maximum price (GMP) was not enforceable due to design errors.

\section{Studies of the Construction Industry}

Studies have attempted to identify the relative performance of the different approaches to delivering construction services. A CII study identified the design-build (DB) process as the most effective followed by CM@Risk and then design-bid-build (DBB) approach (Konchar and Sanvido, 1998). The DB approach was found to be much more effective than the DBB. Interestingly the most efficient process focused on decreasing the need for owner management, direction, and control. However, questions were asked about the validity of the analysis due to the differences in the types of projects being used in the analysis. A follow up and more complete study performed 17 years later by CII and the Charles Pankow Foundation (CPF), could not identify which process was more efficient (Leicht, 2015; Konchar, 1998). Findings included that combined contracts were faster, and cost and quality were driven by procurement and contracting. Findings also revealed success elements, which included:

1. Early involvement of core team.

2. Qualification-based selection.

3. Transparency in cost accounting.

4. Delivery methods alone do not dictate success.

5. Lines between delivery systems are blurred.

6. Owners drive success by selecting strategies that promote team integration and group cohesion.

After studying 204 projects, the CII study is now stating that if owners utilized expert vendors (through prequalification) and if the expert vendors and the owner work together as a cohesive group, the project has a greater chance of success. After the huge number of projects that were studied in 1998 and 2015, the most effective delivery system depends on the owner's constraints and it is highly advantageous to utilize expert vendors who can work together. This supports the industry structure (IS) model, another concept developed in 1991, shown in Figure 1 (Kashiwagi and Badger, 1991). The IS model identifies that poor performance is when the owner/client attempts to exclusively use management, direction and control (MDC) on the project to minimize project risk. Performance increases when the owner utilizes expertise. The movement from low performance to high performance is when the client/buyer replaces MDC with the utilization of expertise and alignment of project roles through increased transparency. In a value based system, the buyer selects a vendor based on expertise and value. This system allows vendors to operate effectively within their own defined scope. The logical progression of the IS model states the following:

1. Owner/client excessive management, direction and control (MDC) of a vendor increases the cost of the delivered service.

2. MDC of a vendor by the buyer minimizes the need of vendor's expertise and the buyer's utilization of the vendor's expertise.

3. MDC of a vendor increases non-transparency, cost and transactions, and decreases the value of expertise and the utilization of expertise.

4. The utilization of vendor expertise instead of MDC will improve value, quality and minimize cost. 




Figure 1: Industry Structure

The Industry Structure (IS) model follows a logical format. It identifies that the client/owner, because they may not be experts in construction, are challenged with the management, direction and control of the vendor, who is an expert in construction delivery. Therefore the IS model states that the more the client/owner utilizes the vendor's expertise, the higher the level of resulting performance.

Table 1 shows the results of the tests conducted by the University of Minnesota and other state organizations. Note the following results (Kashiwagi D., Kashiwagi J., 2013):

1. The client/buyer was responsible for $98 \%$ of all project cost and time deviations.

2. Client satisfaction of the contractor quality was $100 \%$ and the average rating for performance of the contractor was 9.6.

3. Over $50 \%$ of the time, the best value also had the lowest cost.

\begin{tabular}{|l|l|}
\hline Criteria & Rating \\
\hline Number of Projects & 326 \\
\hline Awarded Cost & $\$ 296 \mathrm{M}$ \\
\hline Percent of Projects where BV had lowest cost & $53.00 \%$ \\
\hline Overall Change Order Rate & $15.80 \%$ \\
\hline Due to client & $14.30 \%$ \\
\hline Due to designer & $00.60 \%$ \\
\hline Due to contractor & $00.00 \%$ \\
\hline Due to unforeseen & $00.90 \%$ \\
\hline Overall Delay Rate & $42.90 \%$ \\
\hline Due to client & $31.20 \%$ \\
\hline Due to designer & $04.10 \%$ \\
\hline Due to contractor & $02.20 \%$ \\
\hline Due to unforeseen & $05.40 \%$ \\
\hline Client Satisfaction of Contractor Quality & $100 \%$ \\
\hline Average Contractor Performance Rating & $9.6 / 10$ \\
\hline Number of Completed Project Ratings & 206 \\
\hline
\end{tabular}

Table 1: University of Minnesota Best Value Approach (Kashiwagi and Kashiwagi, 2013)

The same results were also verified by the Dutch Fast-Track project test in the delivery of $\$ 1 B$ of infrastructure repairs (Ibid; Rijt et. al., 2011). The State of Hawaii roofing program shows that owner MDC was the source of poor performance (DAGS, 2002). The cost decreased, the profit margin increased, and the performance issues disappeared (DAGS, 2002). The State of Utah implementation also showed successful implementation of the philosophy in building the 2002 Winter Olympic Housing at the University of Utah (Kashiwagi and Byfield, 2002). The State of Arizona's Department of Environment Quality (ADEQ) recently procured three projects using the same methodology; they found tremendous cost and time savings in just the procurement of the services see Table 2 (Kashiwagi and Kashiwagi, 2014b). 
Job Order Contracting Performance and Industry Analysis

\begin{tabular}{|l|l|l|l|}
\hline Criteria & \% Diff & Traditional & Best Value \\
\hline Required time to evaluate proposals & $-95 \%$ & $286 \mathrm{hrs}$ & $13 \mathrm{hrs}$ \\
\hline Protests & $0 \%$ & 0 & 0 \\
\hline Avg. Customer Satisfaction of process (1-10) & $63 \%$ & 5 & 9 \\
\hline ADEQ Administration Cost & $-96 \%$ & $\$ 98,520.00$ & $\$ 3,840.00$ \\
\hline ADEQ Admin. Cost Savings & $\$ 94,680.00$ & \\
\hline
\end{tabular}

Table 2: ADEQ Best Value Procurement Savings (Kashiwagi. and Kashiwagi, 2014b)

These results also are supported by the IS model, which states that project performance increases when owners are able to better utilize vendors' expertise thereby minimizing the need for MDC.

\section{Cost of Management, Direction and Control (MDC) by Owners}

Studies have attempted to identify the tangible results of implementing a best value process that optimally leverages contractor expertise and minimizes the need to manage, direct, and control the vendor, include:

1. State of Hawaii roofing program saw a $3.07 \%$ drop in roofing costs. It also saw the State of Hawaii project manager able to do 10 times the amount of work (DAGS, 2002).

2. University of Minnesota project manager saw his workload decrease by 90\% (Sullivan, et. al., 2007).

3. The Arizona Department of Environmental Quality selection process saw savings of $\$ 94 \mathrm{~K}$ due to the efficiency of the selection process. The cost of professional services decreased by $100 \%$ on certain comparable projects (Kashiwagi and Kashiwagi, 2014b).

4. The Arizona State University food services purchase of $\$ 400 \mathrm{M}$ worth of food services saw a savings of over $10 \%$. The ASU networking contract saw a 15\% drop with dominantly higher performance (Kashiwagi, 2013).

5. The State of Oklahoma saw a savings of 33\% over the budgeted amount over 13 awarded projects (Kashiwagi et. al., 2003).

6. The Dutch fast track infrastructure projects saw a reduction of cost of $20 \%$, and a decrease in construction time of 25\% (Kashiwagi, et. al. 2013; Rijt, et. al., 2011).

7. The Dallas Independent School District [DISD] saved 14\% off their roofing cost by minimizing MDC. They also utilized the services of their worst performing contractor and received the highest performing roofing systems. DISD saw their method of MDC was responsible for the previous poor roofing performance (Kashiwagi, et. al., 2003).

8. The U.S. Army Medical Command minimized project cost deviations by $5 \%$ by utilizing the Best Value Approach in execution (Kashiwagi, et. al., 2012).

The Best Value Approach, which utilizes the expertise of expert vendors, results in savings of $5-30 \%$. The savings is due to the owner minimizing the use of MDC and utilizing the expertise of the vendors. The expert vendors are selected based on past performance and capability. Contractors and owners discuss the requirements, however, the contractors (not the clients) determine the final scope, the means, and the methods. The savings result from a change in paradigm of the client to utilize the expertise of the expert vendor to deliver services.

\section{Job Order Contracting}

Job Order Contracting (JOC) is a competitively bid, firm-fixed price, Indefinite Delivery Indefinite Quantity (IDIQ) delivery system. JOC is widely considered to be a lean construction method across the industry. Through JOC, a facility owner contracts with a service provider or construction contractor to form a multi-year partnership. Under this system, the contract predefines a unit price book (UPB) that contains a list of service items that a vendor can continuously provide throughout the length of the contract. Originally, the typical UPB had over 40,000 line items that covered every construction task. Each task order is priced by multiplying the UPB cost for each service item used by the contractor's coefficient. Many contracts typically included provisions that would allow for adjustments to the UPB; these processes were typically defined at contract signing. The traditional JOC contract had the following characteristics (Kashiwagi and Sharmani, 1999; Kashiwagi and Bader, 1991):

1. Contractors were engaged early on to participate in the design and scope definition.

2. Contractors competed for a contract by applying a coefficient to the unit price book. The contractor with the lowest coefficient won the contracts. The coefficient captured the cost, general conditions, overhead, and profit.

3. The contracts set a minimum and maximum amount of work per year for each site in a multisite contract.

4. Contractors continuously received task orders from clients.

5. If design work was necessary, the contractor could help manage the design process. Contractors identified different units, and applied their coefficient to calculate total cost. 
6. Owners had the option to extend the timeframe of a JOC.

7. Often, JOC consultants or service providers were employed by owners to facilitate their JOC contracting which included an additional consulting fee.

8. The contract had a minimum and maximum job order dollar amount for the project.

Today, the fundamental purpose of JOC is to increase the efficiency of service delivery, specifically when an owner anticipates a continuous stream of on-site work orders. In using JOC, owners eliminate the need for repetitive procurement cycles. JOC works to simplify the entire delivery system by decreasing the amount of transactions between owners and vendors as well as minimize the time requirements for design, bidding, and construction.

The initial need for JOC arose from the US Army in the early 1980s. Newer facilities established in Europe were facing an increasing demand for continuous construction and maintenance work orders (Williams, 1994; Hoover, 1994). The Supreme Headquarters Allied Powers Europe (SHAPE) was unsatisfied with the overall performance of design-bid-build (DBB) methodologies. DBB was cumbersome to implement on repetitive smallscale projects. DBB required new contracts for every work order, and in a government environment, a new contract means additional oversight, review, and spending. Out of the need to simplify the contracting process, Colonel Harry Mellon at SHAPE conceptualized a delivery system that would ultimately become JOC.

As JOC implementation continued to spread throughout the US military and then eventually to the public, it continued to develop with its focus on rapid response time and high performance results. In 1992, Dr. Bill Badger and Dr. Dean Kashiwagi of ASU initiated a nationwide research effort to measure the performance of JOC. This collaborative group led to the establishment of the Center for Job Order Contracting Excellence (CJE). To this day, CJE's goal is to track the usage and performance of JOC in an effort to provide continuous education to JOC users.

From 1994 - 1998, ASU and CJE created an annual performance survey to measure the current usage of JOC in the military and improve the overall process (Kashiwagi and Sharmani, 1999). These surveys examined data from nearly 200 different military sites. The surveys identified JOC as a high performing delivery system.

The most recent survey on JOC performance (1998) summarized the data from 7 CJE members who managed 80 collective military sites. Every site had a different facility manager who completed the survey. 62 responses were submitted. The results of the surveys are as follows:

1. Comparing JOC performance to traditional process:
a. $85 \%$ felt the JOC system was better than.
b. $14 \%$ felt the system was same as.
c. $2 \%$ felt the system was worse than.

2. Facility owners were satisfied with $95 \%$ of work performed via a JOC system.

3. Construction completed on time: $82 \%$

4. Customer rating of construction (0-10): 8.21

5. Professional level of contractor (0-10): 8.45

\section{Problem}

A challenge facing the JOC industry is the assumption that all projects are the same, and thus the performance of JOC projects is comparable to traditional projects. This concept comes from the low bid award approach. The low bid assumption is that all vendors are "the same" and they all understand the "same thing" and perform in exactly the "same manner."

A more recent approach to identifying value is the Information Measurement Theory (IMT) (Kashiwagi, 2015a). IMT is a deductive logic methodology that uses simple observations and common sense to understand and predict real world events. IMT proposed the following:

1. Natural laws are not created, they are discovered. Natural laws were always there, in every space and in every time. There is no such thing as magic.

2. Every set of conditions based on a location and time is unique. Each set of conditions has a different set of characteristics that makes the set unique. Unique characteristics include time, location, culture, organizations, resources, expectations, and physical conditions.

3. Unique conditions of the past have a relationship with unique conditions of the present at a unique location. Unique conditions of the present will have a relationship with the unique conditions of the future.

4. Everything that happens over time starts from one set of unique conditions and results in another set of unique conditions. 
There are no identical projects. In other words, every unique cause results in a unique effect. This concept, according to IMT, is called a natural law or an axiom of reality. Therefore, IMT proposes that every project, every vendor or contractor, and every client or user is different. Therefore, a supposition that assumes any two projects to be "identical" is fundamentally flawed and will lead to erroneous conclusions (Kashiwagi, 2015a).

Common inaccurate "identical" project assumptions made in the delivery of construction services are as follows:

1. Information (specifications) can be transferred to another person's mind with "exact precision".

2. All vendors interpret specifications the "exact same" way.

3. Vendors have the "exact same" level of expertise, and therefore the lowest cost (price-based award) vendor is the best value vendor.

4. The only way to prove that one delivery system provides a better value is by running two projects that are "exactly the same" and identifying which project had the more optimal results in terms of time and cost.

IMT introduces the concept that all entities and conditions are unique. When people assume that an "apples to apples" comparison can be made, the following may occur:

1. The false assumption requires a tremendous amount of work attempting to create and compare two identical set of conditions, which are "exactly the same."

2. The results of two projects are difficult to validate and therefore the derived conclusions may have little effect in changing traditional practices.

3. Economic analyses, which attempt to prove that a new concept is advantageous in adding value by using a comparison of two "exactly same" projects, may be too difficult and may not have an impact on changing industry practices.

4. The industry may not be able to take advantage of new practices which may increase the value to buyers and expert vendors because of the inability to validate the value of the new practice using the inaccurate assumption of having "exactly the same" conditions.

The implementation of JOC has not been widely accepted due to the reasons above. IMT provides a way to change the paradigm. IMT states that if decision-making is required, it will be highly unlikely that change will be implemented. IMT suggests dominant and simple information that minimizes the need for decision-making. The logical conclusion is the new process is of great value to the client and should be implemented.

\section{Hypothesis}

Using Job Order Contracting (JOC) as a construction delivery method may lead to higher customer satisfaction and better project outcomes and cost savings compared to more traditional methodologies. JOC may additionally increase efficiency by saving time and money, being user-friendly, and project efficiency. Through this report, the researchers hypothesize that JOC may have progressed from an alternative delivery method used only on smaller projects to a major service and procurement delivery system to be effectively used on any project type or size.

\section{Methodology}

This paper intends to determine the performance of Job Order Contracting through the following:

1. Conduct an industry survey of JOC users

2. Perform a research analysis of the results

3. Compare results with other delivery methods

\section{Results}

The goal of this research is to measure the performance and usage of JOC across various industries. In 1998 , it was proposed that JOC is a high performance delivery alternative to more traditional methods (Table 3 ). In the last 20 years, JOC usage has moved from primarily military usage to implementation across all government organizations and some private sector owners. The scope of the research effort is as follows:

- 17 industry stakeholders

- 200 organizations contacted

- 47 owner/client surveys collected

- 13 contractor/vendor surveys collected 
- Projects delivering $\$ 5 \mathrm{~B}$ construction surveyed

- 3,000 data points collected

The current survey effort is a follow-on research to the JOC research conducted from 1994 - 1998 which surveyed military usage of JOC. The latest 1998 survey examined the perspective of facility managers on 62 different military sites. The current research surveyed 47 owners from a variety of industries and 13 JOC general contractors (Table 3).

\begin{tabular}{|l|l|l|l|}
\hline & 1998 Survey, CJE Members & 1998 Survey, Non-CJE Members & Current Survey \\
\hline Number of Owner Responses & 62 & 30 & 47 owners / 13 contractors \\
\hline Average Award Amount to Date & $\$ 5 \mathrm{M}$ & - & $\$ 144 \mathrm{M}$ \\
\hline Average Number of Total Task Orders & 114 & 131 & 1,529 \\
\hline Percent of Satisfactory Projects & $95 \%$ & $90 \%$ & $96 \%$ \\
\hline $\begin{array}{l}\text { Percent of JOC Projects Completed on } \\
\text { Time }\end{array}$ & $82 \%$ & $69 \%$ & $87 \%$ \\
\hline $\begin{array}{l}\text { Percent of JOC Projects Completed on } \\
\text { Budget }\end{array}$ & N/A & N/A & $91 \%$ \\
\hline Quality of Construction Rating & 8.2 & 6.6 & 8.2 \\
\hline Quality of Drawings Rating & 7.8 & 5.1 & 7.2 \\
\hline
\end{tabular}

Table 3: Results Comparison between 1998 JOC Survey and Current JOC Survey

The data from both the 1998 and the current survey show that JOC is continuing to show very high performance compared to other delivery methods and construction performance in general. According to a KPMG International 2015 survey on construction industry performance, only $25 \%$ of projects are completed within $10 \%$ of the original schedule, and only $31 \%$ are completed within $10 \%$ of the original budget (KPMG, 2015). Furthermore, the Construction Industry Institute (CII) identifies that only approximately $2.5 \%$ of all global projects are delivered on time and on budget (PwC, 2009). According to a 2015 KPI report examining the performance of construction projects in the UK, since 1996 cost overrun has increased by 19\% and schedule delays have increased by 14\% (UK Construction Industry, 2011). Despite the industry declining performance over the past 20 years, JOC has shown increasing effectiveness.

In additional to overall performance, this research spans several topics of focus related to administering, tracking, and implementing JOC. Respondents were asked to report on their personal perspectives and satisfaction ratings along with company performance metrics related to project performance (cost/schedule deviations, customer satisfaction ratings, award size, etc.) Among each of these categories, the most impactful analysis results are:

1. $99 \%$ of owner/client participants recommend other owners to use JOC.

2. Owners estimate a $24 \%$ administrative cost savings.

3. Contractors estimate a $21 \%$ overall cost savings.

4. $96 \%$ of projects were completed with satisfactory results.

These results suggest two major findings: first, an overall high satisfaction of JOC among owners/clients, and second, a cost savings from implementing JOC. The remainder of this report will explore these results in further detail along with other comparisons between different owner and contractor perspectives. This section of the report is organized as follows (Table 4):

\begin{tabular}{|c|c|}
\hline Section Name & Major Findings \\
\hline 1. JOC Performance & $\begin{array}{l}\text { - Less than } 5 \% \text { of JOC projects are unsatisfactory } \\
\text { - Owners report } 24 \% \text { cost savings ( } 21 \% \text { for contractors) } \\
\text { - } 87 \% \text { of owner projects delivered on time } \\
-91 \% \text { of owner projects delivered within budget }\end{array}$ \\
\hline 2. JOC cost savings & $\begin{array}{l}\text { - } 75 \% \text { of owners attribute JOC cost savings to decreased procurement time } \\
-52 \% \text { of owners attribute JOC cost savings to decreased PM support time }\end{array}$ \\
\hline $\begin{array}{l}\text { 3. Comparing JOC with other delivery } \\
\text { methods }\end{array}$ & $\begin{array}{l}\text { - Owners believe that JOC shows } 8 \% \text { greater budgetary performance than DBB or DB } \\
\text { - Owners believe that JOC shows } 5 \% \text { greater schedule performance than DBB or DB } \\
\text { - Owners are } 60 \% \text { more satisfied with JOC than DBB or DB } \\
\text { - Owners report a } 65 \% \text { decrease in overall service delivery time using JOC compared to } \\
\text { DBB and DB } \\
\text { - Owner rating for transparency is } 30 \% \text { greater for JOC than traditional delivery } \\
\text { methods. }\end{array}$ \\
\hline 4. JOC Strengths and Weaknesses & $\begin{array}{l}\text { - Strengths: time \& cost savings, simplicity, flexibility, and efficiency. } \\
\text { - Weaknesses: pricing disagreements, lack of JOC industry experience, and poor } \\
\text { communication. }\end{array}$ \\
\hline
\end{tabular}

Table 4: Overall Summary of Research Report

DOI: $10.9790 / 487 X-180902103115$

www.iosrjournals.org

109 | Page 
$<12$ Font Hard Return >

Performance Overview

$<12$ Font Hard Return >

All owner respondents of the survey were classified in five client type categories (university, K12 organizations, state/county/city governments, federal government, and private organizations). Each of these clients was identified through stakeholder references and online resources. Survey respondents have a varying level of experience with project types, sizes, and costs. For contractor respondents to the survey, 13 contractors responded, all of which are general contractors who perform various types of work (HVAC, electrical, GC, restoration, etc.) The following show details of the owners and contractors that responded:

\section{Owners (47)}

- Years of experience ranges: 2 - 26 years (10 average)

- Total historic award amount of all JOCs: \$0.15M - \$2B (\$144 average)

- Average cost of each task order: $\$ 100 \mathrm{~K}-\$ 9.9 \mathrm{M}(\$ 3.3 \mathrm{M}$ average)

- Total number of Job/Task orders to date: $2-30,000$

- Total number of active master agreements: $0-200$

\section{Contractors (13)}

- Years in business: 12 - 78 (33 average)

- Years using JOC: 4 - 27 (11 average)

- Number of JOCs with different owners: 1 - 31 (14 average)

Both clients and contractors were asked to report on the performance of the projects that they either used JOC on or participated in (Table 5). The key findings are as follows:

\begin{tabular}{|l|l|l|l|}
\hline & \multicolumn{1}{|c|}{ Unit } & \multicolumn{1}{|c|}{ Owners } & \multicolumn{1}{|c|}{ Contractors } \\
\hline Average Percent of Cost Savings Through Using JOC & $\%$ & $24 \%$ & $21 \%$ \\
\hline Percent of Projects Completed With Satisfactory Results & $\%$ & $96 \%$ & - \\
\hline Percent of Projects On-Time & $\%$ & $87 \%$ & $94 \%$ \\
\hline Percent of Projects On-Budget & $\%$ & $91 \%$ & $89 \%$ \\
\hline Overall Satisfaction With JOC & $(1-5)$ & 4.1 & 4.3 \\
\hline Flexibility & $(1-5)$ & 4.3 & 3.9 \\
\hline Transparency & $(1-5)$ & 4.1 & 4.1 \\
\hline The Importance of Technology in JOC & $(1-5)$ & 4.1 & - \\
\hline
\end{tabular}

Table 5: Owner and Contractor Performance Using JOC

1. Owners report that only $4 \%$ projects are unsatisfactory (the highest rate is $15 \%$ while 32 of the other respondents reported a rate of less than $10 \%$ ).

2. The highest maximum reported contract duration is 8 years, while the rest of the respondents report a duration of 1-5 years, the overall average being 3 years.

3. $18 \%$ of respondents use 1 contractor per JOC, $78 \%$ of respondents report using on average 3 or fewer contractors, and $14 \%$ average 10 or more contractors per JOC.

4. $64 \%$ of respondents issue 10 or fewer job/task orders per JOC contract, while $18 \%$ report issuing 20 or more (the greatest reported number being 80 for a client's 5 year contracts)

5. $79 \%$ of respondents maintain facilities.

6. Out of 42 respondents, only 1 would suggest not using JOC to another owner.

7. $77 \%$ of owners report that they use support software to perform JOC.

\section{Cost Savings}

Owners were asked to estimate the total amount of administrative cost savings compared to traditional methods and contractors were asked to estimate total cost savings seen throughout the project. Administrative cost savings primarily comes from the amount of time needed to procure, administer and manage contracts, but may also come from legal fees or costs associated with documentation requirements and revisions. Out of 44 owners that responded to having experienced cost savings, only 18 (42\%) could quantify how much they saved, reporting on average $24 \%$ savings (highest $80 \%$ and lowest $0 \%$ ). Of the 13 contractors, they report a $21 \%$ cost savings. Savings depend greatly on users' current and past delivery methods. To gain a better understanding of the source of savings, 
respondents were asked to list all of the sources of probable cost savings. The top sources (and the percentage that listed the source) are as follows:

\section{Owner Survey (44)}

- Procurement Administrative Time (75\%)

- Project Manager Support Time (52\%)

- Design and Drawing Costs (30\%)

- Decreased Documentation Demands (30\%)

- Minimized Admin Transactions (14\%)

- $\quad$ Decreased Support Staff (9\%)

\section{Contractor Survey (13)}

- Acquiring and Bidding New Projects (73\%)

- Decreased Change Orders (45\%)

- Decreased Time Requirements (27\%)

- Design (27\%)

- Overhead (27\%)

\section{Comparing JOC to Other Delivery Methods}

Early in its development, JOC was used for smaller scoped projects. Today, JOC is being used on a variety of projects with varying scopes and sizes. JOC is now able to compete with more traditional delivery methods. Owners provided data on $60 \mathrm{JOC}$ contracts that encompass 8,000 job/task orders in the survey. The average cost of each task order ranges from $\$ 100 \mathrm{~K}-\$ 9.9 \mathrm{M}$. All survey respondents (owners and contractors) reported using a variety of other delivery methods in conjunction with JOC (Design-Bid-Build [DBB], Design-Build [DB], Construction Manager at Risk [CM@R], etc.). Owners/clients were asked to report on any observable performance differences between JOC, DBB, and DB.

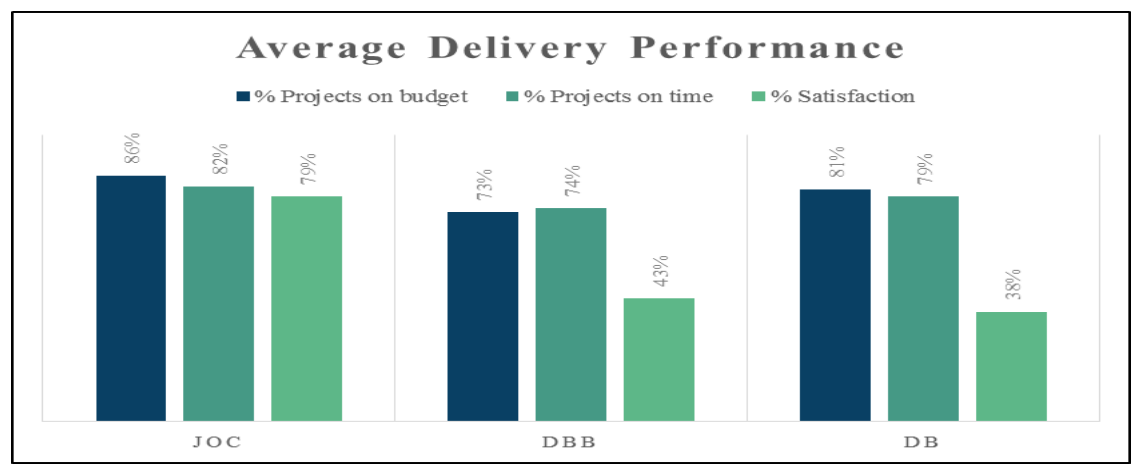

Figure 2: Owner perception of JOC $(n=31)$, DBB $(n=19)$, and DB $(n=11)$ project performance

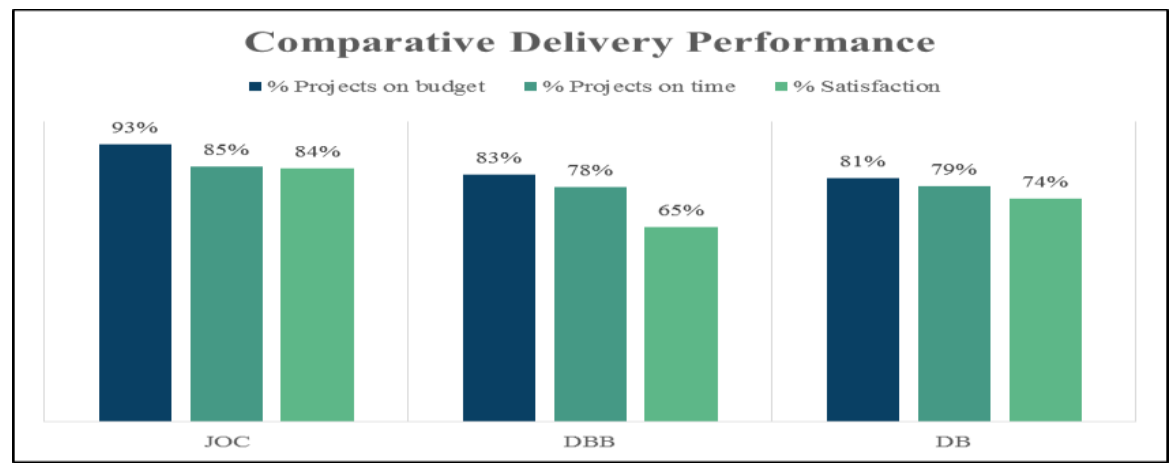

Figure 3: The perceived performance of JOC, DBB, and DB by owners who reported metrics for on all three delivery systems $(\mathrm{n}=17)$

The average project performance (schedule and budget deviations) of JOC, DBB, and DB is shown in Figure 2. Figure 3 shows the comparative project performance for owners who reported data from JOC, DBB, and DBB. Both figures suggest that JOC projects are more often delivered on time and on budget compared to DBB and DB projects of similar scopes. In regards to budgetary performance, JOC is perceived to be $8 \%$ higher than the average DBB and DB. In regards to schedule performance, JOC is perceived to be 5\% higher than the average DBB and DB. There were more survey responses for JOC performance (31) than DBB (19) and DB (11). 
In the survey, owners/clients were asked to rate their relative satisfaction of JOC, DBB, and DB for various aspects of project delivery on a scale of $1-5$ (5 is high, 1 is low) (Table 6). Overall, respondents are most satisfied with JOC, followed by DBB, and then DB. Survey respondents are $60 \%$ more satisfied on average with JOC than DBB and DB. Owners believe JOC to be more transparent (30\% average) and flexible (76\% average) than the other delivery methods. These percent differences are calculated by comparing the percent difference between the ratings of each survey response.

The only category where DBB outperforms JOC is in quality of design drawings and services. The number of responses vary between each delivery service; JOC having the most and DB having the least. Additional research should be done to widen the scope of survey responses. In regards to contractors' perspective, they report a greater satisfaction in using JOC along with a higher project performance (percent on budget and on time). The results in Table 7 are similar to owner perspective..

\begin{tabular}{|l|l|l|l|}
\hline & JOC & DBB & DB \\
\hline Number of Responses & 33 & 24 & 14 \\
\hline Overall Satisfaction rating (1-5) & 4.1 & 2.3 & 2.0 \\
\hline Quality of Construction (1-5) & 4.1 & 2.5 & 2.3 \\
\hline Quality of Design Services (1-5) & 3.6 & 3.8 & 2.3 \\
\hline Quality of Design Drawings (1-5) & 3.6 & 4.1 & 2.3 \\
\hline Level of Transparency (1-5) & 4.2 & 2.3 & 2.2 \\
\hline Level of Flexibility (1-5) & 4.3 & 2.0 & 2.0 \\
\hline Allows the achievement of organizational goals (1-5) & 4.3 & 2.5 & 2.4 \\
\hline Average Rating (1-5) & $\mathbf{4 . 0}$ & $\mathbf{2 . 8}$ & $\mathbf{2 . 2}$ \\
\hline
\end{tabular}

Table 6: Satisfaction Rating of Owners/Clients for JOC, DBB, and DB.

\begin{tabular}{|l|l|l|l|}
\hline & \multicolumn{1}{|c|}{ JOC } & \multicolumn{1}{|c|}{ DBB } & \multicolumn{1}{|c|}{ DB } \\
\hline Number of responses & 11 & 8 & 10 \\
\hline Contractor's Satisfaction Rating & 4.3 & 2.8 & 3.7 \\
\hline Average Customer Satisfaction Rating of the Contractor & 4.4 & 3.3 & 4.1 \\
\hline \% Projects on budget & $89 \%$ & $60 \%$ & $69 \%$ \\
\hline \% Projects on time & $94 \%$ & $63 \%$ & $73 \%$ \\
\hline
\end{tabular}

Table 7: Contractor Perspective of JOC Compared to DBB and DB.



Figure 4: Time Spent in the Primary Phases of Service Delivery

Owners/Clients were asked to estimate the total amount of time spent in each delivery phase of JOC, DBB, and DB given a similar project size and scope (Figure 4). The researchers contacted respondents to verify that only projects of similar size and scope were being considered to ensure accuracy. This information illustrates that with JOC, the time spent on procurement and design is minimized so the major resources of time and funding can be devoted to the actual construction. 


\section{JOC Strengths and Weaknesses}

JOC was designed to minimize any non-value related activities delivering construction projects, creating a more efficient way to complete projects. The major benefits of JOC are as follows:

1) Minimizes time spent on procurement up to $97 \%$ ( $72 \%$ average)

2) Increases flexibility to achieve organizational goals by $300 \%$ ( $76 \%$ average)

3) Decreases time it takes to deliver a project up to $83 \%$ (59\% average)

4) Enables owners to utilize the expertise of contractors

5) Rated as $30 \%$ more transparent

\section{The Main Weaknesses of the JOC Process are as Follows:}

1) Hiring a contractor with a lower level of expertise affects multiple projects.

2) Due to minimized transactions and information exchange, if the owner hires a non-expert contractor multiple issues will arise without the owner knowing.

3) The owner is not as involved in the technical work, thus if the vendor is not an expert, it can lead to multiple project issues and misunderstandings.

4) JOC is a relatively new delivery method, compared to traditional DBB. Thus, many owners do not have a good understanding of best practices and legal limitations of it.

5) JOC seeks to save money through a structure that minimizes transactions. The cost and time savings makes up for minor deviations in costs of specific construction activities. Owners not aware of this are often caught-up in negotiating costs of construction.

\section{Conclusion}

The construction industry has struggled with delivering high performing services for the last 20 years. Multiple studies have shown that the majority of issues that occur on projects are due to low-bid selection of contractors and associated attempts at management, direction, and control (MDC) of a contractor. As MDC increases and the usage of best practices decrease, the ability to use contractor expertise diminishes. The most successful solutions have been found to minimize the need for MDC and increase the utilization of the vendor's expertise, while increasing transparency between all parties involved in project delivery, which includes JOC. JOC was developed by the military as a delivery method that minimized the owner's administration and management of projects using an indefinite delivery indefinite quantity (IDIQ) contract to hire a high performing contractor that could respond quickly to work needed by the client, which minimized cost disputes. A national survey (1998) found that $94 \%$ of owners believe that JOC was more efficient than traditional delivery systems and owners were satisfied with $87 \%$ of JOC work. Due to its success with the military, JOC spread to other government agencies and is now utilized by private organizations. JOC, widely considered to be a LEAN construction method, is structured to minimize required transactions in the supply chain and increases the utilization of the vendors' expertise. The JOC system has been the only delivery model to be able to protect an owner against issues caused by a traditional low bid environment by increasing transparency.

This research surveyed 55 owners across the U.S. to identify how well JOC is performing with the changing construction industry. The major concerns owners had with the use of JOC were:

- Understanding the fundamentals and industry best practices in implementing JOC

- Pricing disagreements that arise from the Unit Price Book (UPB)

- The roles of owners and contractors, and proper communication between the two

- How to avoid poor performing contractors

- The type of projects that JOC is best suited for

The results of the study also found that JOC has maintained its high performance. With the greatest success being when the system is used with its original requirements and intent (best practices). Some of the most impactful results of the survey are as follows:

1. $99 \%$ of facility owners recommend JOC.

2. $96 \%$ of JOC projects are completed with satisfactory results.

3. $87 \%$ of JO projects are delivered on time.

4. $91 \%$ of JOC projects are delivered on budget.

5. Owners estimate an average of $24 \%$ administrative cost savings by using JOC instead of traditional delivery methods.

6. Compared to other delivery methods, JOC increase transparency by $30 \%$. 
Survey data showed that both clients that have used JOC for larger and smaller projects/task orders (up to $\$ 9.9 \mathrm{M}$ ) have experienced high performance (time, cost, quality). Overall, the survey found that regardless of what type of construction was performed or what the size of the projects, JOC performed the same. When the survey participants were asked to compare their satisfaction and the performance of JOC to other delivery systems (DBB and DB), clients were found to feel that JOC was a better delivery system in terms of delivery time, cost, and satisfaction. Some of the key findings are as follows:

1. JOC projects are $8 \%$ more on budget.

2. JOC projects are $5 \%$ more on time.

3. JOC projects have a $60 \%$ greater client satisfaction rating.

Clients and contractors also identified several valuable aspects of JOC that could not be quantified. They are as follows:

1. $98 \%$ of respondents report that JOC reduces costs (primarily in procurement, project management, and design).

2. $82 \%$ claim that JOC increases overall project efficiency because it requires less time to deliver the project, it is simple to use, and flexible for a variety of project types and sizes.

3. $96 \%$ of clients agreed that the largest motivation for using JOC is its ability to reduce time. The next most important factors were its simplicity and flexibility.

The research has found that overall, JOC is a high performing delivery method, regardless of how the system is used. Nevertheless, the research suggests that JOC performance may increase largely when users adhere to traditional JOC best practices. In its traditional usage, and today, JOC focuses on decreasing the need for owners to manage, direct, and control contractors by:

1. Optimizing the number of contract awards to best fit the program volume thereby eliminating unnecessary contractor competition and thus ensuring maximum usage of contractor expertise

2. Encouraging early contractor involvement to provide more scope clarification

3. Ensuring accurate unit price book items before contract signing so as to provide thorough coverage for anticipate task orders

4. Allowing contract involvement with project designs instead of procuring design work completely outside of the JOC project

According to the Construction Industry Institute, $2.5 \%$ of all global projects are delivered on time and on budget resulting in a high change order rate (PwC, 2009). Research suggests that using the Best Value Approach can save owners up to $30 \%$ (Kashiwagi, et. al., 2013). This paper identifies that using JOC results in an average cost savings of $24 \%$. The cost of running a JOC program with the assistance of a JOC consultant only ranges from $2 \%$ to $10 \%$ (PBSRG, 2014). Deductive logic identifies that owners can definitely save money and increase performance by using JOC.

\section{References}

[1]. Adrian, J., 2001, Improving Construction Productivity, Construction Productivity Newsletter, 12(6)

[2]. Associated General Contractors of America, 2004, Project delivery systems for construction, Arlington, VA: Associated General Contractors of America

[3]. Chikuni, A. \& Hendrik P., 2012, The Impact of Procurement Systems on the Outcome of Public Projects, Presented at RICS COBRA 2012, Las Vegas, NV

[4]. Gransberg, D., Koch, J., \& Molenaar, K., 2006, Preparing for design-build projects: a primer for owners, engineers, and contractors, Reston, VA: ASCE Press

[5]. Hoover C. S. 1994, Job-Order Construction Quantification - An Application of Fuzzy Thinking. Master's Thesis, Arizona Sate University. Tempe, Arizona.

[6]. Kashiwagi, D. 2015a. 2015 Information Measurement Theory, Tempe, AZ: KSM Inc., 2015

[7]. Kashiwagi, D. 2015b. 2015 Best Value Approach, Tempe, AZ: KSM Inc., 2015

[8]. Kashiwagi, J. 2013, Factors of Success in Performance Information Procurement System/Performance Information Risk Management System, Ph.D. Thesis, Proefschrift Technishe Universiteit Delft.

[9]. Kashiwagi, D. T. and Badger, W. W. 1991, Job Order Contracting: A New Contracting Technique for Maintenance and Repair of Construction Projects, Cost Engineering 33 (3) pp. 21-24, March

[10]. Kashiwagi, D. T. and Byfield, R., 2002, "State of Utah Performance Information Procurement System Tests," ASCE: Journal of Construction Engineering and Management, 128 (4) pp. 338-347, July

[11]. Kashiwagi, D.T. and Parmar, D., 2004, Past Performance Information in the Construction Industry, ASC Proceedings of the 40th Annual ASC Conference Brigham Young University-Provo, UT., CD T22 (April 8, 2004)

[12]. Kashiwagi, D., and Kashiwagi, J. 2013, Dutch Best Value Effort. RICS COBRA Conference 2013, New Delhi, India, pp. 356-363 (September 10-12, 2013) 
[13]. Kashiwagi, D. and Kashiwagi J., 2014b, Arizona Department of Environmental Quality Best Value Effort Documentation, Unpublished raw data

[14]. Kashiwagi, D., Kashiwagi, J., Smithwick, J., Kashiwgi, I., Kashiwgai A., 2012, The Source of Degradation of the Construction Industry Performance, Journal for advancement of performance information and value, 4 (2), 206-222

[15]. Kashiwagi, D., Kashiwagi, J., Sullivan K., 2013, The Research Model that Revolutionized the Dutch Construction Industry, Journal for advancement of performance information and value, 4 (2), 147-160

[16]. Kashiwagi, D., Savicky, J. and Parmar, D., 2003, Case Study of the Dallas Independent School District's Construction Value, Association of Researchers in Construction Management (ARCOM) 19th Annual Conference, University of Brighton, UK, pp13-21 (September 3, 2003)

[17]. Kashiwagi, D. T., \& Al Sharmani, Z. 1999. Development of the Job Order Contracting (JOC) Process for the 21st Century. Journal of Construction Education, 4(2), 187-195.

[18]. Konchar, M., \& Sanvido, V., 1998, Comparison of U. S. project delivery systems, Journal of Construction Engineering and Management, Nov/Dec 1998, pg 435- 444

[19]. KPMG International, Climbing the curve, Global Construction Survey 2015", KPMG International Cooperative available at: http://www.kpmg.com/global/en/issuesandinsights/articlespublications/global-construction-survey/pages/global-construction-survey2015.aspx (accessed 10 May 2015).

[20]. Leicht, R. M., Molenaar, K. R., Messner, J. I., Franz, B. W., and Esmaeili, B. 2015. Maximizing Success in Integrated Projects: An Owner's Guide. Version 0.9, May. Available at http://bim.psu.edu/delivery

[21]. Lepatner, Barry, B., 2007, Broken Buildings, Busted Budgets, The University of Chicago Press, United States of America: Chicago

[22]. Ohrn, Greg. The Influence of Job-order-contracting as a Construction Project Delivery Method on Owner Satisfaction. ProQuest, 2009.

[23]. UK Construction Industry KPIs - Industry Performance Report 2011, 2011 Industry Performance Report, Based on the UK Construction Industry Key Performance Indicators', pp. 1-30

[24]. PBSRG, 2014, Interview with The Gordian Group, The Gordian Group Office, 700 Longwater Dr., Norwell, MA, July 29, 2014

[25]. PricewaterhouseCoopers (PwC), 2009. "Need to know: Delivering capital project value in the downturn." [https://www.pwc.com/co/es/energia-mineria-y-servicios-publicos/assets/need-to-know-eum-capital-projects.pdf] Accessed September $16,2015$.

[26]. Rijt, J., Wiebe, W., Vis, C., Santema, S., 2011, Best Value at the Directorate-General for Public Works and Water Management in The Netherlands: A Case Study of the Procurement of Infrastructure Project Worth $\$ 1.200 \mathrm{M}$, Journal for advancement of performance information and value, $3(1), 90-100$

[27]. Rivera, A. O. 2014. Impact of a Non-Traditional Research Approach Case Study on the Performance Based Studies Research Group (PBSRG) (Master's Thesis, ARIZONA STATE UNIVERSITY).

[28]. State of Hawaii Department of Accounting and General Services (DAGS), 2002, Report for Senate Concurrent Resolution NO. 39 Requesting a Review of the Performance Information Procurement System, PIPS Advisory Committee. Honolulu, HI, 2002

[29]. Sullivan, K., Savicky, J., Kashiwagi, D., Perkins, M. and Grussing, J., 2007 "Transitioning to an Information Environment: Performance Research in Large Capital Projects and Facility Management Group" Fourth International Conference on Construction in the 21st Century (CITC-IV): Accelerating Innovation in Engineering, Management, and Technology, Gold Coast, Australia, CD-T21 (July 11, 2007)

[30]. Williams, J. (1994). Exploring and implementing job order contracting. Unpublished master's thesis. University of Alaska, Fairbanks, Alaska. 